\title{
The Historical Background of the Popularity of Genealogies in Korea
}

Sangwoo Han

Postdoctoral Researcher, Universitat Autònoma de Barcelona

Edifici MRA 125, Campus de la UAB 08193 Bellaterra (Barcelona), Spain.

sangwoo.han@uab.cat

Acknowledgments

This work received fundings from the Postdoctoral Research Program of Sungkyunkwan University (2018) and the European Research Council (ERC) under the European Union's Horizon 2020 research and innovation program (No 758347).

\section{Copyright}

Each instance of use of the Contribution, or any part of it, must include the copyright notice that appears on the issue of the Journal in which the Contribution is first published and a full bibliographic citation to the Journal as published by SAGE.

\begin{abstract}
The widespread trend for compiling genealogies in Korea is known to have emerged around the seventeenth century. To explain this, scholars have pointed to the influence of Neo-Confucianism and similarities with Chinese genealogical traditions. However, this study focuses on the inclusionary and exclusionary forces within Korean genealogy, with the former drawing more
\end{abstract}


members into the genealogy and the latter resulting in fewer family members being included. In particular, this study draws attention to the selective recording of patrilineal family members and to the frequent inclusion of relatives-in-law in Korean genealogies. The social hierarchy system of premodern Korea appears to have been the most crucial factor in determining the particular features and popularity of Korean genealogies, and in this paper I draw attention to how this accounts for the differences between Korean genealogy and the genealogical traditions of other East Asian societies.

Keywords: genealogy, kinship, family, social hierarchy system, Korean history 


\section{Introduction}

The phenomena of son preference, primogeniture, and universal marriage in Korean society have long been considered a legacy of the traditional family system and culture. ${ }^{1}$

Scholars regarded the Korean concept of genealogy as a typical example of a kinship culture developed on the basis of Confucian ideas of patrilineal kinship, which changed the recording patterns of genealogies in Korea from the seventeenth century onwards. ${ }^{2}$ Based on the fact that most referred to Confucianism in their prefaces when explaining the reasons for their, compilation, Korean genealogies were cited as convincing proof of the Confucian transformation of the idea of kinship. ${ }^{3}$ However, some studies are now questioning the importance of Confucianism in genealogical composition by examining other factors, such as rivalry among patrilineal kin members ${ }^{4}$ and the diversity of people included in Korean genealogies. ${ }^{5}$ This new development in research indicates that the previous leading studies may have overemphasized the importance of the Confucian transformation.

This article takes issue with the previous centrality of Confucianism in scholarly explanations of Korean genealogy. It will consider the historical background and social stratification of premodern Korean society as causes of the unique features of Korea genealogies by comparing the Korean genealogies with those of other East Asian countries. ${ }^{6}$ Exploring the various recording patterns found within Korean genealogies and comparing them with other East Asian countries is not only helpful for understanding the structure and characteristics of the genealogies themselves but will also shed light on the Korean concept of kinship.

I will argue that it is vital to consider the type of genealogy in question, since this played a deciding role in what compositional rules were followed. In particular, I will introduce three types of genealogy (taedongbo, p'abo, and ch'onghappo) which possess different structures and 
recording patterns depending on the purpose of their compilation. I will illustrate why the various purposes of genealogies resulted in different recording patterns for both non-paternal relatives and patrilineal male members.

\section{Prior studies of East-Asian genealogies and kinship}

The Korean family slowly became more patrilineal from the seventeenth century onwards under the influence of Neo-Confucianism. Neo-Confucianism arrived in the Korean Peninsula around the fourteenth century, and over time affected Korean society in many ways, not least in the concept of what constituted the "family."

Zhu Xi (1130-1200), a Neo-Confucianist of Song China, quoting the ancient classic of divination, the Book of Changes (Yiching), understood the relationship between ancestors and descendants as a continuation of $q i$ (氣, in Korean $\left.c h{ }^{\prime} i\right)$ : “Things that accord in tone vibrate together. Things that have affinity in their inmost natures (qi) seek one another." 7 This phrase describes the core idea of patrilineal kinship - the concept of the transmission of qi (in Korean, tongch'iron, 同氣論). Even though this concept took centuries to penetrate Korean society after its introduction, scholars have agreed that the "Confucian transformation," which included the kinship system, was completed by the seventeenth century. ${ }^{8}$ They also considered the NeoConfucianism concept of patriarchal kinship to have remained dominant in Korea until the 1960s. ${ }^{9}$

When we consider Korean genealogies from the perspective of East-Asian genealogies and kinship, we must first focus on the general and particular features of genealogies compiled in 
Korea. In terms of genealogical pedigree, ordinary Korean genealogies employ a particular method for recording information about descent group members and their relatives. This method originated in China and records not only the direct ancestors of the compilers but also collateral (non-direct) ancestors, such as uncles, grand-uncles, and great-grand-uncles. ${ }^{10}$ This type of genealogy developed its morphology during China's Song dynasty and later spread to Korea and Vietnam. ${ }^{11}$ In Song society, as a response to social mobility facilitated by the civil examination system, long-established families rediscovered their ancient pedigrees and started to compile multi-volume genealogies. ${ }^{12}$ This weakening of social hierarchies was a significant opportunity for the practice of genealogy to develop as it promoted the formation and development of lineage associations based on patrilineal kinship in local society. ${ }^{13}$ The introduction of civil examinations removed the opportunity for advancement into officialdom that had previously existed purely on a hereditary basis. As a result, to retain social status in local society, paternal kinship associations were under pressure to create conditions likely to produce successful examination candidates. ${ }^{14}$ Simultaneously, Neo-Confucian classicists and philosophers such as Su Xun (1009-1066) encouraged the compilation of genealogies, ${ }^{15}$ which became essential for elite families. ${ }^{16}$ In southeastern China, where conflicts between local families had become increasingly frequent, kinship groups attempted to organize themselves in order to respond to and win disputes with other kin associations. ${ }^{17}$ In addition, local governments also took advantage of kin associations to extend their power in local society, which also positively influenced the development of Chinese kin associations. ${ }^{18}$

In this situation, genealogies that recorded all direct and collateral paternal relatives were a useful tool for kin associations. An essential component of Chinese genealogies is the 'genealogical table' (世表), which lists all paternal members of each generation by order of birth 
and serves to define the order of kin members and provide a sense of belonging. Such genealogical tables, however, are not a common feature of Korean, Vietnamese, or Japanese genealogies. Instead, these countries developed the 'family tree' (世系) from the main components of Chinese genealogy. While the genealogical table uniformly recorded family members by generation, emphasizing that they all inherited the same $q i$ from the originator, the family tree considered the flow and direction of $q i$, and recorded family members with a focus on the various relationships of each member. ${ }^{19}$

The genealogies of Tokugawa Japan (1600-1868) were compiled in the form of a single line that linked the heir of each generation; they recorded the heir and his siblings, but provided no information about sibling descendants. This characteristic of Japanese genealogy is attributed to the fact that Tokugawa society maintained a strict social hierarchy, whereby only one of the children could succeed to the father's status - a system known as katoku (家督). Sometimes, a relative other than a child of the household head could be the one to inherit this status, for example a grandchild, brother, nephew, cousin, uncle, or even a son-in-law, brother-in-law or grandson-in-law. There are also many cases in which households were inherited by adopted sons from other families, so that the proportion of household succession by the eldest son had already decreased dramatically by the eighteenth century. ${ }^{20}$

Thus, Japanese genealogy differed significantly from Chinese genealogy, which was based on "patrilineage" or descent by blood. Most notably, Kanei shokakei zuden (寬永諸家系圖傳, 1644) and Kansei chūshū shokafu (寬政重修諸家譜, 1812), compiled by the Tokugawa shogunate, demonstrate the recording pattern used in Japanese genealogies. The shogunate monopolized genealogical production and collected information about family lines and 
family members of elite groups such as daimyō (feudal lords) and their hatamoto vassals as a means of social control. Consequently, Japanese genealogies were important for identifying one's place in the hierarchy.

Moving to a different part of East Asia and examining the Ryukyu Kingdom (modern day Okinawa), which was annexed by Japan in 1879 , we observe that, prior to the annexation, Ryukyu genealogies did not record the collateral lines of householders. Ryukyu genealogy used the Chinese-style genealogical table but did not record siblings' descendants. This feature of Ryukyu genealogy indicates that their social hierarchy system was similar to that of Japan. In 1689, Ryukyu established a public office that administered the genealogies of the elite class. As a result, the government required every elite family to submit their genealogy and report any changes, so that the genealogies could be confirmed and receive an official seal. ${ }^{21}$ In this way, the Ryukyu government maintained control over the elite groups.

The composition of Korean genealogy is like that of the Lê (1533-1789) and Nguyễn (1802-1945) dynasties of Vietnam. These genealogies recorded collateral family members in the same way as China and Korea. However, Vietnamese genealogies had a narrower range, recording only the fifth or sixth generation of descendants from the originator. ${ }^{22}$ The existence of patrilineal genealogies shows that the Vietnamese family system was influenced by Chinese culture, especially Confucianism. For instance, the introduction of Confucian-oriented laws during the Nguyen dynasty attempted to endow men with more power and authority in the family. ${ }^{23}$ Although such laws failed to penetrate the lower classes, Confucianism caused upperclass families to adopt the Chinese style of genealogy, which was more patriarchal and structured. ${ }^{24}$ In this respect, Vietnamese and Korean genealogies are remarkably similar.

According to one study, Vietnamese genealogy attempts to show social status through 
marital relationships, ${ }^{25}$ while other studies assert that the similar features mentioned above reflect common aspects of Southeast-Asian family culture rather than Chinese influence. ${ }^{26}$ In Vietnamese society and families, the status of women was relatively high. ${ }^{27}$ Although the Confucian-oriented Nguyen dynasty attempted to endow men with power and authority within the family, it was difficult to change the high status of women in real life. ${ }^{28}$ Even now, matrilineal traditions remain entrenched in Southeast-Asian families, which is not the case in China. ${ }^{29}$

The similarities between Korean and Vietnamese genealogies after the seventeenth century call into question the established explanation that Korean kinship is very similar to patrilineal Chinese kinship. The type of genealogy in premodern Korea that is most like the pattern seen in Chinese genealogies is Yangse kyebo (養世系譜), ${ }^{30}$ a genealogy of eunuchs. Because eunuchs enjoyed high social status and official posts at court, they used to marry and adopt sons to ensure their family succession and the continued right to the position of eunuch at court for their descendents. They did not need to adopt daughters, which meant their genealogies only contained records of patrilineal male individuals.

As already indicated in prior studies, Neo-Confucianism was only one of many factors that led to changes in Korean genealogy and kinship around the seventeenth century. It means that we should re-examine Korean genealogies in an attempt to remove patrilineal bias from our understanding of premodern Korean families. In the next section, this paper will focus on the recording patterns and information about in-law relatives in Korean genealogies, because their existence in genealogies reveals the unique features of Korean kinship compared with Chinese and Japanese kinship.

\section{In-law relatives in Korean genealogy}


Previous studies have shown that the structure, composition, and recording format of premodern Korean genealogies changed around the seventeenth century. As a result, scholars have traditionally divided Korean genealogy into two stages based on this change. One specific and important feature of early genealogies was that they usually recorded not only patrilineal male kin but also daughters and their descendants.

In the oldest extant genealogy, Andong Kwŏnssi sŏnghwabo (安東權氏成化譜, 1476), ${ }^{31}$ a

genealogy of the Andong Kwŏn Clan, the compilers recorded not only patrilineal descent groups but also descendants of daughters, with different family names and without setting limits on the number of generations. As a result, of the 9,000 persons recorded in this genealogy, only 380 (5 percent of the total) have the family name Andong Kworn. ${ }^{32}$ The second oldest genealogy, Munhwa Ryussi kajŏngbo (文化柳氏嘉靖譜, 1565), ${ }^{33}$ also records information about the descendants of daughters. In addition, the Chinyang Hassi sebo (晉陽河氏世譜) ${ }^{34}$ compiled by the Chinyang Ha clan in 1606, records many children of daughters and relatives-in-law, resulting in only 7 percent of the total of 6,089 persons carrying the family name Chinyang Ha. ${ }^{35}$ The compiler included his direct forefathers, collateral forefathers, forefathers of his wife, and forefathers of his daughter-in-law in this genealogy; living in the countryside a long way from the capital, it is likely that he adopted this complicated method in order to prove his connection with royalty. ${ }^{36}$

Table 1

One of the changes in genealogies compiled from the seventeenth century onwards is that the 
descendents of daughters are only recorded for their children's and grandchildren's generations. This change appears to be part of the process of organizing family members patrilineally, which was the main purpose of Chinese genealogies. From this point onwards, genealogies mainly recorded the son's line and excluded the son-in-law's line. ${ }^{37}$ The differences between earlier and later genealogies provide evidence of the consolidation of patrilineality ${ }^{38}$. Furthermore, as the social strata of genealogy compilers expanded into the lower classes, it also shows the consolidation of patrilineal kinship throughout various layers of society. ${ }^{39}$

Although the practice of recording daughters' descendants declined in later genealogies compared with earlier ones, it did not completely cease. Even if we only consider the number of sons-in-law recorded in genealogies, it becomes clear that the idea that later-stage genealogies were only for the same surname group is a misunderstanding. When we calculate the number of wives' fathers and sons-in-law's fathers, as well as the children of daughters, the proportion of those in the genealogy with other family names is much greater than that of those carrying the patrilineal surname.

We should draw particular attention to the appearance of the wife's ancestors in laterstage genealogies. Earlier genealogies contained either no information about wives and their ancestors or, for instance in the genealogies of the Andong Kwŏn (1476), Munhwa Ryu (1565), and Chinyang $\mathrm{Ha}$ (1606), only brief references. However, later genealogies contained considerable information about the wife's family. Typically, these recorded not only information related to the wife herself, but also her father's name and official post. Some dominant lineages recorded the wife's "four forefathers (sajo 四祖)": her father, grandfather, great-grandfather, and maternal grandfather. Consequently, the proportion of those bearing another family name did not decline in later-stage genealogies compared with earlier ones. 
Let us explore some specific examples of how Korean genealogies recorded more marriage-related relatives than Chinese genealogies. After compiling their first genealogy, the Andong Kim clan changed their method of recording, so that their second genealogy in 1790 records children by gender rather than birth order with the sons listed first, while the third genealogy in 1833 records the deceased wife's "four forefathers." The introductory note to the fourth edition in 1878 states that this genealogy is the first to record the "four forefathers" of a wife who was still living. ${ }^{40}$

The fact that information on a wife's "four forefathers" was recorded tells us that certain genealogies were trying to prove the superior social status of their members by highlighting their marriage networks. We can also see this in the household registers of Chosŏn Korea (1392-1897), which are used by scholars as a way to identify someone's social status. ${ }^{41}$ Powerful families were able to provide this information about their "four forefathers", whereas lesser families often lacked this genealogical information or did not have have successful ancestors within this range.

The richness of the information about people with a different, non-patrilineal family name in Korean genealogies, including the wife, becomes more apparent when comparison is made with Chinese genealogies. The genealogies of Ming (1368-1644) and Qing (1644-1912) China generally recorded the name of a daughter's husband but not a son's wife, or else they just recorded the wife's family name. ${ }^{42}$ Occasionally, Chinese genealogies recorded information about a wife's father, but did not include any other genealogical information. ${ }^{43}$

This raises the question of what led to this unique characteristic of Korean genealogies of providing plentiful information about women and in-laws. Some scholars think it was a remnant of the kinship system and culture of Koryŏ Korea (918-1392), the dynasty that preceded Chosŏn Korea. ${ }^{44}$ However, the fact that information about women and their families survived in 
genealogies even after the seventeenth century, when Neo-Confucianism started to penetrate Korean society, makes us reconsider the common understanding of the Confucian transformation and the transition to patrilineality. In this regard, we should also consider the impact of the social hierarchy on Korean society until the end of the nineteenth century. I will consider this point in the final section of this study. However, in the next chapter, this study attempts to classify the different types of Korean genealogies and interpret their features before introducing the two major types of Korean genealogy that were prevalent in Korean society after the seventeenth century.

\section{The coexistence of taedongbo and p'abo genealogies}

The primary function of a family genealogy is to record information about family members. Both of the two types of genealogy described in this section share this same goal. When we observe the structure and recording patterns of genealogies, however, we realize that two opposing forces are at work: one draws in individuals and includes more members of the family ("inclusionary factors"), while the other is concerned with exclusion and differentiation and pushes them out ("exclusionary factors"). At times when the inclusionary forces were stronger, genealogies tended to include more family members, but when the exclusionary forces were stronger, more individuals were excluded from the genealogies. This feature of Korean genealogy has been defined as a dual mechanism. ${ }^{45}$

The best way to see the dual mechanism at work in kinship relationships is to examine different kinds of genealogies. So, let us explore the genealogies of several elite lineages to illustrate the features of premodern Korean families and kinship, as distinct from other East Asian countries, by analyzing the relationship of persons included in these genealogies in the late 
Chosŏn period. Many later-stage genealogies tended to record all the members of the clan. The compilers described Neo-Confucian ideas such as the concept of the transmission of $q i$ to support their intentions. They considered all men with the same family name to be descendants of one originator, and therefore tried to extend the range of recording to all social classes across the Korean Peninsula. Genealogies of this type are called taedongbo (大同譜) and are typical examples of inclusive genealogy.

\section{Figure 1}

In Figure 1 and the following figures, the small triangles refer to male members, the sons of the clan or lineage. The triangles at the top of the tree are the originators of each clan or lineage. Figure 1 shows the range of members recorded in taedongbo. Taedongbo attempted to record not only the descent of the line of the powerful or formal heirs, but also included all the descendants of the originator of the clan. Although the name taedongbo was not used before the nineteenth century, it aptly demonstrates the intention of this type of genealogy. Taedongbo means a comprehensive genealogy, ${ }^{46}$ and Deuchler explains it as a "higher-order genealogy.. ${ }^{, 47}$ Thus, the taedongbo, which included persons of lower social status, is considered to be a critical piece of evidence showing that patrilineal relatives organized beyond the demarcations of social class. In this way, Korean kinship associations are similar to those of southeastern Ming-Qing China.

The compilation of a taedongbo did not always provide a sense of belonging to all the lineages and families within the clan. As an example, we can trace several editions of the genealogy of the Andong Kim clan, which includes the most well-known and prominent lineage in eighteenth- and nineteenth-century Korea. The genealogy series of this clan consistently 
distinguishes and records some segments, $p^{\prime} a$ (派), which were not confirmed as clan members, in a subordinate position at the end of volumes. The Andong Kim clan started to compile their first genealogy in $1719 .{ }^{48}$ This genealogy comprised six main segments and ten unconfirmed smaller segments at the end of the genealogy. These unconfirmed families increased to fourteen in the second genealogy in $1790,{ }^{49}$ and to eighteen in the third and fourth editions in $1833 .{ }^{50}$ Eventually, the records of the eighteen unconfirmed families came to comprise one-tenth of the entire volume of the genealogy that was published in $1878 .^{51}$ These families were finally recognized as clan members, sharing the same $q i$ from the same originator, in the fifth genealogy in $1926 .{ }^{52}$ From this point onwards, they are included within the main text of the genealogy rather than at the end as a kind of appendix. However, one of the unconfirmed families present in the first edition is entirely absent from the fifth edition of the genealogy. ${ }^{53}$

As we can see from the case of the Andong Kim clan, Korean genealogies did not aim for perfect integration of all of the patrilineal male members, nor was it essentially possible, as all Korean genealogies, even the taedongbo, were affected by factors such as social status that pushed possible candidates for inclusion out or relegated them to an inferior status. In this respect, Korean genealogy differs from Chinese genealogy and is distinct from the ideology of Neo-Confucianism.

In some cases, prominent segments of the clan disagreed with the taedongbo practice of extending the recording range to persons of lower status in accordance with the Neo-Confucian concept of $q i$ transmission. This gave rise to p'abo (派譜) or "segment genealogy", a type of family genealogy that records only one or a number of specific segments in a clan. The degree of 
consanguinity among family members inevitably becomes diluted with passing generations and, as a result, patrilineal kin groups consistently separated into smaller demographic and social segments. In this situation, p'abo became popular, coexisting alongside taedongbo. Indeed, many more $p$ 'abo than taedongbo were compiled in Korean society after the seventeenth century.

Few scholars have examined the exclusionary aspects of Korean genealogies, as the genealogical records have typically been regarded as evidence of patrilineal consolidation. However, it is obvious that there are some features of Korean genealogy that distinguish it from Chinese genealogy; one of these is the tendency to exclude people, which is more evident in the p'abo than the taedongbo. By studying such features and their effect on genealogy, we can determine the social and historical background of the current characteristics of Korean genealogy and kinship. The next chapter will examine examples of such exclusionary forces within kin members and lineages in clan genealogies.

\section{Exclusionary aspects of genealogies}

P'abo were more exclusionary than taedongbo as they recorded only those who were considered to be indisputably related by blood to the common ancestor of the segment, and tended to exclude persons of lower status, for example, sons of a lower class mother, even if they belonged to the same lineage. In order to be recorded in p'abo, individuals had to fulfill certain conditions of blood relationship, high social status, and even political orientation. When it was necessary to accommodate some families or small segments that did not meet these conditions, p'abo begrudgingly recorded them at the end of the volume. In this way, genealogies had the force to include or exclude kin members. $P^{\prime}$ 'abo also had the force to organize and unify kin, but their cohesive force was not as strong as that of Chinese genealogies, and their range of unity was 
arbitrary. Figure 2 illustrates the compiling range of $p$ 'abo.

Figure 2

The p'abo sometimes intentionally declined to record some candidates even if they met the conditions of blood relationship and social status. The case of the Hapch'ŏn Yi clan is evidence of the p'abo's arbitrary recording. The Hapch'ŏn Yi have compiled more than sixty genealogies since the seventeenth century, and most of them are p'abo.

The case of Mukkok village shows the exclusionary factors operating in small communities. Two small segments belonging to the Hapch'ŏn Yi clan and living in the same village of Mukkok published several p'abo from the eighteenth century onwards. ${ }^{54}$ It was clear that the two segments in this village originated from the same ancestor, although they had initially been unaware they were related and had entered their surnames differently in the household registers as Hapch'ŏn Yi and Kangyang Yi. The taedongbo of the Hapch’ŏn Yi clan in 1761 records both of these segments in Mukkok village. After 1761, however, the bigger and more powerful segment excluded the smaller one from their genealogies, even though they were related by blood and resided in the same village. ${ }^{55}$ This resulted in competition between the two segments, leading each one to start compiling genealogies that excluded the other. As a result, three $p^{\prime}$ abo were created simultaneously for this clan in $1926 .^{56}$

Ignoring and excluding was the simplest way to discriminate against unwanted family members in genealogies. Illegitimate sons (children of women that were not the single official spouse, in academic literature in English sometimes also referred to as "secondary sons") and their descendants were easy targets of exclusion from genealogies because they had inferior and 
unstable family status. Sons born to concubines faced both social and legal discrimination in comparison with legitimate sons in premodern Korean society. Their status was inferior not only within the family but also in the genealogical records.

The most severe discriminatory measure taken against illegitimate children in genealogies was to not list their offspring. As a result, there are more individuals without heirs among the illegitimate than the legitimate in all genealogies that this study examined of the Andong Kim, Yŏnan Yi, Chinsŏng Yi, and Hapch’ŏn Yi clans.

A total of 599 members from the fifteenth to the twenty-first generation in the Andong Kim (1833) and Yŏnan Yi (1863) genealogies have differing numbers of sons by status in the family. For example, the mean number of sons of the illegitimate (1.13) is lower than that of the legitimate (1.47). Even if we exclude those without any sons at all, the mean number of sons of the illegitimate (1.31) is still lower than the equivalent figure for the legitimate (1.54). It is possible that this gap is the result of the difference in the economic and social situation of legitimate and illegitimate sons, but it is more likely that the genealogy deliberately omitted the descendants of illegitimate sons.

That there was obvious discrimination against the illegitimate in the recording patterns of the genealogies becomes evident when we compare them with their Chinese and Vietnamese equivalents. Chinese genealogies distinguished illegitimate sons by writing "born from a concubine (側室 or 側出)" under their name in small letters but did not discriminate against them in any other way in the written records. Discrimination in the family and in society was also less severe, and Chinese illegitimate sons, unlike Korean ones, could be candidates for the civil examinations. Furthermore, an illegitimate son could inherit the family line with the same rights as a legitimate son, if the family had no legitimate sons. ${ }^{57}$ 
Unlike in China and Vietnam, Korean genealogies used the title sŏja (庶子, "illegitimate son") in front of a name in large letters to distinguish them from the legitimate sons recorded as cha (子, "son”). Genealogies recorded illegitimate sons and illegitimate daughters after legitimate sons and daughters. In later genealogies, daughters were written after sons regardless of their birth order, but illegitimate sons appeared after legitimate daughters which meant that illegitimate daughters appeared at the very end. Korean genealogies also recorded information about illegitimate children differently. Most genealogies recorded the literary pseudonyms and years of birth and death for legitimate sons but failed to do so for the illegitimate. They also described the deaths of the illegitimate as $\mathrm{mol}$ (歿, “dead") rather than chol (卒, “deceased") and used the word $c h$ 'wi (娶 “married”) rather than pae (配, “wedded”) for their marriages. Many genealogies justified these discriminations by claiming it was to "distinguish between the noble (the legitimate) and the vulgar (the illegitimate)." ${ }^{, 58}$

It was in the twentieth century that the description of "illegitimate (庶)" began to disappear from genealogies after the Chosŏn government abolished the practice of discriminating against illegitimate sons when appointing government officials in 1894. Even so, many genealogies continued to identify illegitimate sons by recording their information in different ways, and some still use "illegitimate" even to this day, making the achievement of equality among family members in genealogies still a work in progress.

Discrimination against the illegitimate in genealogies is an example of the exclusionary force associated with classifying family members. Furthermore, when we consider that 
genealogies omitted illegitimate offspring born to concubines and lower-class women, we realize that the Neo-Confucian concept of shared $q i$ did not fully penetrate Korean society, whereas such individuals were included in Chinese genealogies and considered as fully recognized members as long as they shared the same father. In the case of Korea, it is easy to imagine that a lawful wife, who enjoyed high status within the family, would not allow her husband to grant the same status as her children to the illegitimate children of a concubine from a lower class.

The social hierarchy system in Korea was a strong contributing factor to exclusionary forces and was abolished in 1894. These exclusionary forces hindered the consolidation of patrilineal kin of different social status and contradicted the prefaces of genealogies that emphasized the Neo-Confucian principle of shared $q i$.

In the following section, I will introduce another type of Korean genealogy, the ch'onghappo, which was popular until the middle of the twentieth century. It has received very little scholarly attention, but ch'onghappo help us to understand the purpose of the compilation of genealogies in Korean society.

\section{Ch'onghappo - another type of genealogy}

The gap created by the inclusionary and exclusionary forces in taedongbo and p'abo grew over time. Some compilers started to collect the family records of those who met specific criteria from all the clans. Their attempts led to another type of genealogy, ch'onghappo (綜合譜 or "comprehensive genealogy"), which became popular from the seventeenth century onwards. Unlike taedongbo with their emphasis on the unity of the clan and p'abo dealing with only specific segments, ch'onghappo combined family records from many different clans. Therefore, ch'onghappo are similar in nature to an encyclopedia of all the families and clans of the Korean 
Peninsula. ${ }^{59}$

It is important to recall that one of the purposes of genealogy is to prove the supremacy of a social elite group. The way that taedongbo recorded a wide range of paternal relatives had failed to satisfy this desire among some of the elite class, who wanted to selectively record only the most successful family lines from particular clans. This led the elite groups to favour $p$ 'abo over taedongbo, as the latter allowed too many politically heterogeneous families from various social strata to be included in a clan. However, the elite groups also found it convenient to acknowledge certain relations through the ch'onghappo, as these allowed connections to be drawn based on political affiliation and hierarchical status between successful family lines from diverse clans.

In ch'onghappo, too, we can observe inclusionary and exclusionary forces at work. Ch'onghappo exhibit a strong inclusionary force as they cast the net wide to include all clans, but their strict categories for inclusion, such as social class, occupation, success in officialdom, political orientation, and regional affiliation demonstrate a strong exclusionary force ${ }^{60}$ Compilers ignored information about those who did not meet these categories, which meant that this type of genealogy was not suitable for Neo-Confucian patrilineal purposes. Figure 3 is a model of ch'onghappo compilation based on information gathered from several clans and lineages.

\section{Figure 3}

Appearing first in the seventeenth century, ch'onghappo increased in number over time and continued to be popular until the first half of the twentieth century. Haedong sŏngwŏn (海東姓苑) and Ssijok wŏllyu (氏族源流) are typical examples of ch'onghappo written in the 
seventeenth century. Ssijok worllyu is a collection of the most famous and powerful family lines from 540 clans. Among those compiled in the nineteenth century, Tongsŏnggo (東姓考), ${ }^{61}$ Sŏngwŏllok (姓源錄), ${ }^{62}$ and Man'gabo (萬家譜), ${ }^{63}$ compiled by the Haenam Yun family, were especially well known. Many volumes of ch'onghappo were compiled in the first half of the twentieth century, including Paekssi t'ongbo (百氏通譜), ${ }^{64}$ Ch'ŏnggu ssibo (靑丘氏譜, 1925), ${ }^{65}$ Mansŏng taedongbo (萬姓大同譜, 1931), ${ }^{66}$ and some have continued to be made more recently, such as Han'guk kyehaengbo (韓國系行譜, 1992). ${ }^{67}$

Ch'onghappo based on official posts, political orientation, and place of residence increased from the eighteenth century onwards. For example, Chamyŏngbo (䙃縜譜) ${ }^{68}$ and Chinshinbo (緇紳譜) ${ }^{69}$ recorded the family lines of those who held official posts in the central government. Some genealogies collected the family lines of bureaucrats according to their official career paths. Munbo (文譜) ${ }^{70}$ was for those who had passed the civil service examinations, $M u b o$ (武譜) ${ }^{71}$ for those successful in the military service examinations, and $\breve{U} m b o$ (蔭譜) ${ }^{72}$ for those who had obtained positions as a result of an ancestor's meritorious deeds. Nambo (南譜) ${ }^{73}$ and Pukpo (北譜 $)^{74}$ collected family lines based on political orientation. ${ }^{75}$

It is clear that the social hierarchy system in Korea was an important factor in the emergence and popularity of ch'onghappo, as they selected family lines from numerous clans 
based on social status and supremacy. For 500 years, a small pool of bureaucrats who had passed the civil examination administered the Chosŏn government, and so the number of successful candidates for the civil examinations and the number of officials in the central government were the standards of supremacy for elite families. However, because it was difficult to produce successful examination candidates consistently, another standard based on intermarriage between elite families also came to be accepted in society.

The Korean elite always practised homogamy, choosing their marriage partners based on shared socioeconomic status, which was why Korean genealogies contained rich information concerning in-law relatives. Ch'onghappo served as a major source for the study of genealogy and the networks in elite Korean society until the early twentieth century. Indeed, the most famous ch'onghappo, Mansŏng taedongbo, compiled in 1931, comprised thousands of family lines from 508 clans and recorded every man together with his father-in-law's name. ${ }^{76}$

We will now turn our attention to the social hierarchy system that existed in Korean society until the end of the nineteenth century and see how it influenced Korean genealogies, including ch'onghappo, and gave them their unique character.

\section{Social hierarchy and information in genealogies}

The unique information and recording patterns of Korean genealogical records provide clues to understanding genealogy itself, as well as Korean society and kinship. What types of information do the genealogies provide? First, there are names: given name, alternative names, names acquired in adulthood, and literary pseudonyms. They also provide information on siblings and children, including both sons and daughters, legitimate and illegitimate. There is also information about adoption: sons adopted into and out of the family, with their birth father. The 
most important information for historical demography in genealogies are the year and date of births and deaths. The date of death was particularly important in Korean genealogies due to the custom for descendants to offer sacrifices on the day their ancestors died. As most of the dead were buried in the mountains, the genealogies recorded the locations of their tombs so that sacrifices could be made there.

One of the essential parts of the personal information recorded in genealogies was the career record. Serving as a government official was the highest goal for the elite in Chosŏn Korea, with the shortest and most reliable route to achieving this being the state civil examinations. However, these examinations were extremely difficult to pass and less than thirty candidates were successful every year. Since it was a great honor for the whole clan and lineage segment to have produced a successful candidate, genealogies recorded this information faithfully. The compilers also considered it important to record the career information of government officials who obtained their positions by passing lower-grade exams such as military exams and preliminary exams or due to the meritorious acts of their ancestors.

Table 2 shows the information provided about the forefathers of wives and sons-in-law in the genealogies of the elite families that belonged to the Andong Kim, Yŏnan Yi, Sunch'ŏn Pak, Chinsŏng Yi, and Hapch'ŏn Yi clans. In this table, we can see that all genealogies recorded in-law relatives with different family names. Similarly as with Table 1, Table 2 shows a situation in which the number of individuals with the clan name are outnumbered by people with different family names.

Table 2 
In Table 2, we must also note that the relationships recorded in the genealogies of each clan differ. First, the genealogies of the most prominent lineages living in Seoul and its surroundings in the eighteenth and nineteenth centuries - the Andong Kim and Yŏnan Yi-included the greatest number of in-law relatives in their genealogies. As previously mentioned, these recorded the wife's "four forefathers," as well as the son-in-law's relatives (son, son-in-law, and son-inlaw's father). This pattern of recording relatives with other surnames is similar to the genealogy of the Sunch'ŏn Pak clan, descendants of the loyal retainer Pak P'aengnyŏn, which produced many candidates who were successful in the civil service examinations in Taegu and Ch'ungju.

This inclusion of marriage networks and in-law relatives stands in striking contrast to Chinese genealogies, in which they were omitted as the woman's part in marriage was viewed in Chinese culture as family divergence from the patrilineal line. ${ }^{77}$ Why, then, did Korean genealogies record so many in-law relatives? To understand this, we need to look at the origin of the concept of the "four forefathers." Until the fifteenth century, the social standing of an elite family was certified by the government, using the record of the "four forefathers" (father, grandfather, great-grandfather, and maternal grandfather) of the household head and his wife in the household register. When the compiling of genealogies began in the fifteenth century, they took the place of household registers in proving one's social status. ${ }^{78}$

Strong demand by elite families for recognition of their social status contributed to the development of ancestry trees based on records of the forefathers of the in-laws. The Tongnae Chŏnggajang oenae p'algodo (東萊鄭家藏外內八高圖), ${ }^{79}$ compiled in 1881 , is one of the most elaborate examples of this type of ancestry tree. The compiler collected ancestry charts starting with himself and reaching back to his thirteenth-generation forefathers and foremothers. In a study comparing Korea with other East Asian countries, Miyajima Hiroshi asserts that the 
compiler hoped in this way to prove his superior social status in the genealogy by showing both his own and his forefathers' excellent marriage networks. ${ }^{80}$ As time passed, ancestry charts based on the "four forefathers" records expanded to include maternal ancestors more comprehensively than before. Indeed, marriage was a crucial strategy for maintaining social status in premodern Korea. $^{81}$

Genealogies of these powerful clans included not only those who bore the family name but also many other in-law members with a variety of family names. As a result, these genealogies recorded the names of many who were important bureaucrats in the political sphere at the time. Recording the "four forefathers" of the wife's side was a convenient strategy for showing superiority as it allowed compilers to increase the number of government officials in the genealogies.

Let us examine the genealogy of the Ch'ungjŏnggong segment of the Sunch'ŏn Pak clan, compiled in $1899 .{ }^{82}$ It records a total of 1,329 male members born between the early seventeenth and the middle of the nineteenth century. Among them, we find that 54 members held a central government post. However, after considering the "four forefathers" records, the number of officials sharply increases to include 77 officials among 1,237 fathers-in-law, 80 officials among 752 grandfathers-in-law, 89 officials among 121 great grandfathers-in-law, and 51 officials among 574 maternal grandfathers-in-law on the wives' side. As a result of the inclusion of the "four forefathers," the Sunch'ŏn Pak genealogy was able to increase its number of government officials more than fourfold.

A different pattern of recording can be seen in the genealogies of two other clans, the Chinsŏng Yi and Hapch'ŏn Yi, compiled in the early twentieth century. Unlike the genealogies of dominant lineages, these two genealogies record patrilineal relatives and the wife's father among 
the "four forefathers" of the wife's side, as well as daughters' children and sons-in-law. The reason may be that there were not many officials among the "four forefathers" of their wives and so it would not have been socially advantageous to record them. Therefore, instead of "four forefathers," the genealogies of the Chinsŏng Yi and Hapch'ŏn Yi recorded the famous ancestors on the wife's side, going back as far as was necessary to include them. For example, they might mention that their wife's most well-known ancestor lived hundreds of years ago.

As mentioned, the main reason for recording relatives with other family names in the genealogy was to increase a family's social status by including as many government officials and other successful relatives as possible. Differences in recording patterns of the "four forefathers," can therefore be ascribed to fact that clans that lived in the provinces and had relatively few bureaucrats in their extended families had little reason to include them in their genealogies. And indeed we find exactly this reason stated in the introductory notes of the genealogy of Andong Kim in 1878: "Let anyone who has no father with an official position among their "four forefathers, write down a famous ancestor regardless of their generation, and so prevent the information from being insufficient." $\$ 83$

In order to include more successful candidates in civil exams and government officials, prominent and powerful clans included more non-paternal than paternal relatives in their genealogies. It was not easy, however, for less prominent and politically disadvantaged local families to produce successful candidates after the seventeenth century and this is reflected in the different pattern of their genealogies.

The Korean social hierarchy system that was maintained until 1894 was one of the most important factors that influenced Korean kinship relations and the way they were recorded and categorized in genealogies. It was this system, along with the relatively high status of women in 
the family, that resulted in the inclusion of abundant information about in-law relationships in Korean genealogies. In this, they resemble Vietnamese genealogies and also the family trees of the European nobility.

Although premodern Korea's social hierarchy was stricter than that of Ming and Qing China, it allowed for greater social mobility than in Tokugawa Japan where class divisions were rigidly enforced. ${ }^{84}$ This enables us to see how the character of the social hierarchy system was the defining factor in the birth and development of the different types of Korean genealogies - the taedongbo, p'abo, and ch'onghappo. The rigid class system of Tokugawa Japan led to strong exclusionary tendencies in the practice of family succession and genealogies accordingly were produced only for the single direct line of heirs. In Vietnamese genealogies, inclusionary factors were not strong enough to draw in a wide range of patrilineal family members. In Korea, however, we have seen how strong inclusionary and exclusionary tendencies were both at work as a result of the adoption of Neo-Confucianism while also maintaining the social hierarchy system. This resulted in the development of different types of genealogy depending on the relative strength of these two tendencies. In summary, the popularity of genealogy compilation from the seventeenth to the twentieth century should be explained by considering not only the Confucian concept of the family concept but also the characteristics of Korean society with its hierarchical family culture and competition between elite families.

\section{Conclusion}

The composition and recording patterns of Korean genealogies differ from those of other East Asian countries. Although scholars have emphasized the similarities between Korean and Chinese genealogies, which both record the whole patrilineal descent group including collateral 
relatives, we should remember that several differemt types of Korean genealogy were produced between the seventeenth and twentieth centuries. This study has introduced three common types of Korean genealogy and examined their historical and social background.

The study has proposed two opposing forces - inclusionary (the tendency to include more members) and exclusionary (the tendency to exclude members) - as the reason for the emergence of various types of genealogies. The relative strength of each force reflected social factors and determined which type of genealogy a family used. For example, taedongbo, which aimed to record all the descendants of the originator of the clan, exhibit a stronger inclusionary force than p'abo, which only recorded one or a number of significant segments of a clan, usually those with higher status. P'abo discriminated against siblings of socially inferior status, especially illegitimate children and their descendants; in this respect they differed from Chinese genealogies and reflected the discrimination against the illegitimate in Chosŏn Korean society. Strong exclusionary forces can also be seen in ch'onghappo, which were inclusionary in the sense that they recorded various family lines from almost every clan, but were exclusionary in their strict criteria for inclusion based on social status, occupation, political orientation, and regional affiliation.

This study focused on the information and recording patterns of relatives-in-law as a means of deepening our understanding of Korean genealogy and elite society. The abundance of information recorded on the wife's side reveals that the purpose of Korean genealogies in the later stages was to affirm hierarchical superiority, unlike the case in China. This study has explored the number of in-law relatives that were recorded in various types of genealogies until the late nineteenth and early twentieth centuries and argued that this was a means of establishing elite status and gaining access to marriage with higher status families. In this context, this paper 
has also examined the specific increase in the number of government officials recorded in genealogies and shown that it was easy for powerful and prestigious families to boost this number by recording the wife's "four forefathers."

In conclusion, this study posits that the social hierarchy system should be considered the primary determining factor for the recording and categorizing patterns found in Korean genealogies and the underlying reason that many genealogies do not neatly fit the patrilineal male-centered principles of Neo-Confucianism. The kinship system and genealogies of the Korean elite must be interpreted in the context of the social hierarchy and the bureaucratic system, based on the state civil examination, that made elite society more competitive and promoted the search for ways to assert superiority. An understanding of the diverse relationships of premodern Korean families and the social factors that determined them cannot succeed without a thorough reflection on the characteristics of the genealogies that are such an integral part of Korean tradition.

Table 1 Numbers and percentages of members in genealogies by family name and status in the family

\begin{tabular}{|c|c|c|c|c|c|c|c|}
\hline \multirow{2}{*}{$\begin{array}{l}\text { Family } \\
\text { name of }\end{array}$} & \multirow{2}{*}{$\begin{array}{l}\text { Status in } \\
\text { the family }\end{array}$} & \multicolumn{2}{|c|}{$\begin{array}{l}\text { Andong Kim } \\
\quad(1833)\end{array}$} & \multicolumn{2}{|c|}{$\begin{array}{c}\text { Yŏnan Yi } \\
(1863)\end{array}$} & \multicolumn{2}{|c|}{$\begin{array}{c}\text { Sunch’ŏn Pak } \\
\text { (1899) }\end{array}$} \\
\hline & & $\mathrm{N}$ & $\%$ & $\mathrm{~N}$ & $\%$ & $\mathrm{~N}$ & $\%$ \\
\hline The clan & Son & 400 & 27.8 & 770 & 26.2 & 1,504 & 36.4 \\
\hline \multirow{3}{*}{ Other clans } & Father-in-law & 423 & 29.4 & 935 & 31.8 & 1,305 & 31.6 \\
\hline & Son-in-law & 331 & 23.0 & 627 & 21.3 & 792 & 19.1 \\
\hline & $\begin{array}{l}\text { Father of } \\
\text { son-in-law }\end{array}$ & 285 & 19.8 & 609 & 20.7 & 535 & 12.9 \\
\hline \multicolumn{2}{|c|}{ Total } & 1,439 & 100.0 & 2,941 & 100.0 & 4,136 & 100.0 \\
\hline
\end{tabular}


Table 2 Forefathers of wives and sons-in-law in genealogies

\begin{tabular}{|c|c|c|c|c|c|c|}
\hline Genealogies of & $\begin{array}{l}\text { Andong K } \\
\text { Yŏnan }\end{array}$ & $\begin{array}{l}\mathrm{m}(1833) \\
\mathrm{i}(1863)\end{array}$ & Sunch'ŏn & ak (1899) & $\begin{array}{l}\text { Chinsŏng } \\
\text { Hapch'ŏr }\end{array}$ & $\begin{array}{l}Y i(1912) \\
Y i(1926)\end{array}$ \\
\hline \multirow{2}{*}{ Status in a family } & Legit & Illegit & Legit & Illegit & Legit & Illegit \\
\hline & son dau & son dau & son dau & son dau & son dau & son dau \\
\hline son-in-law & 0 & 0 & 0 & 0 & 0 & 0 \\
\hline fa-in-law & $0 \quad 0$ & ○ & 0 & O & 0 & \\
\hline grnfa-in-law & 0 & & $0 \quad 0$ & $\mathrm{O}$ & & \\
\hline grt-grnfa-in-law & O & & 0 & & & \\
\hline mat-grnfa-in-law & O & & 0 & & & \\
\hline fa of son-in-law & 0 & & & & & \\
\hline
\end{tabular}

* legit: legitimate, illegit: illegitimate, dau: daughter, fa: father, grnfa: grandfather, grt: great, mat: maternal 


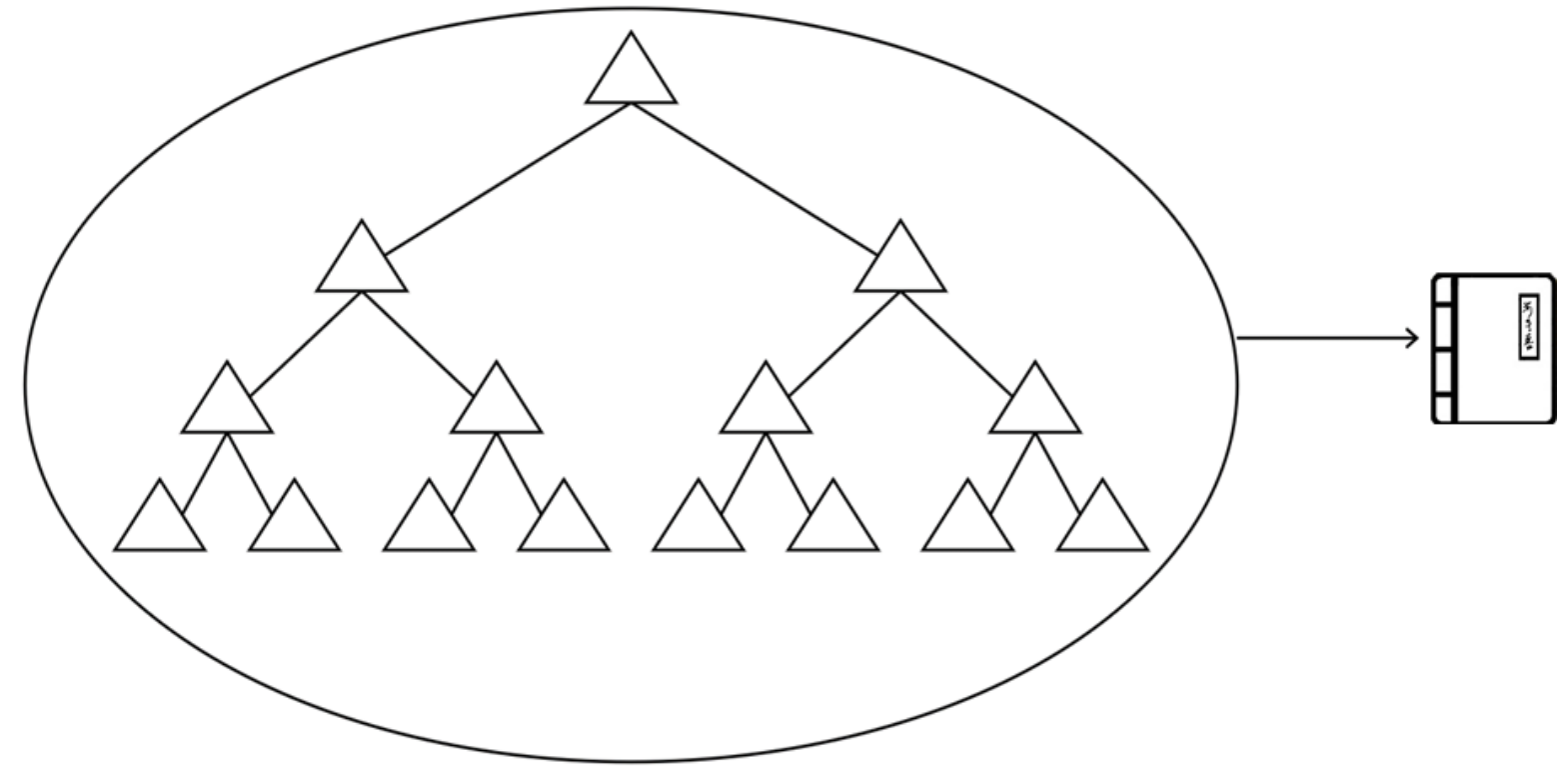

Figure 1 Taedongbo

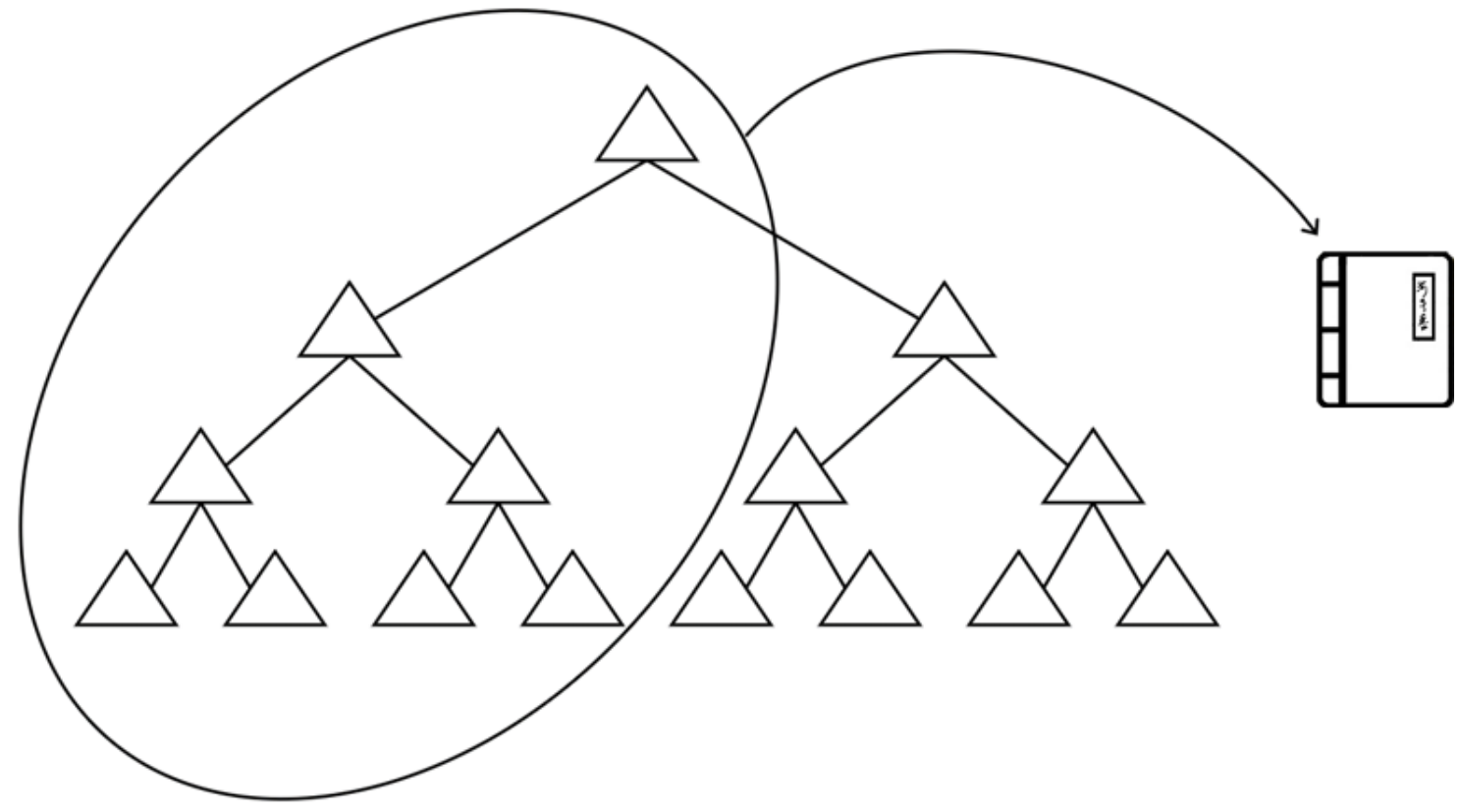

Figure 2 Pabo 


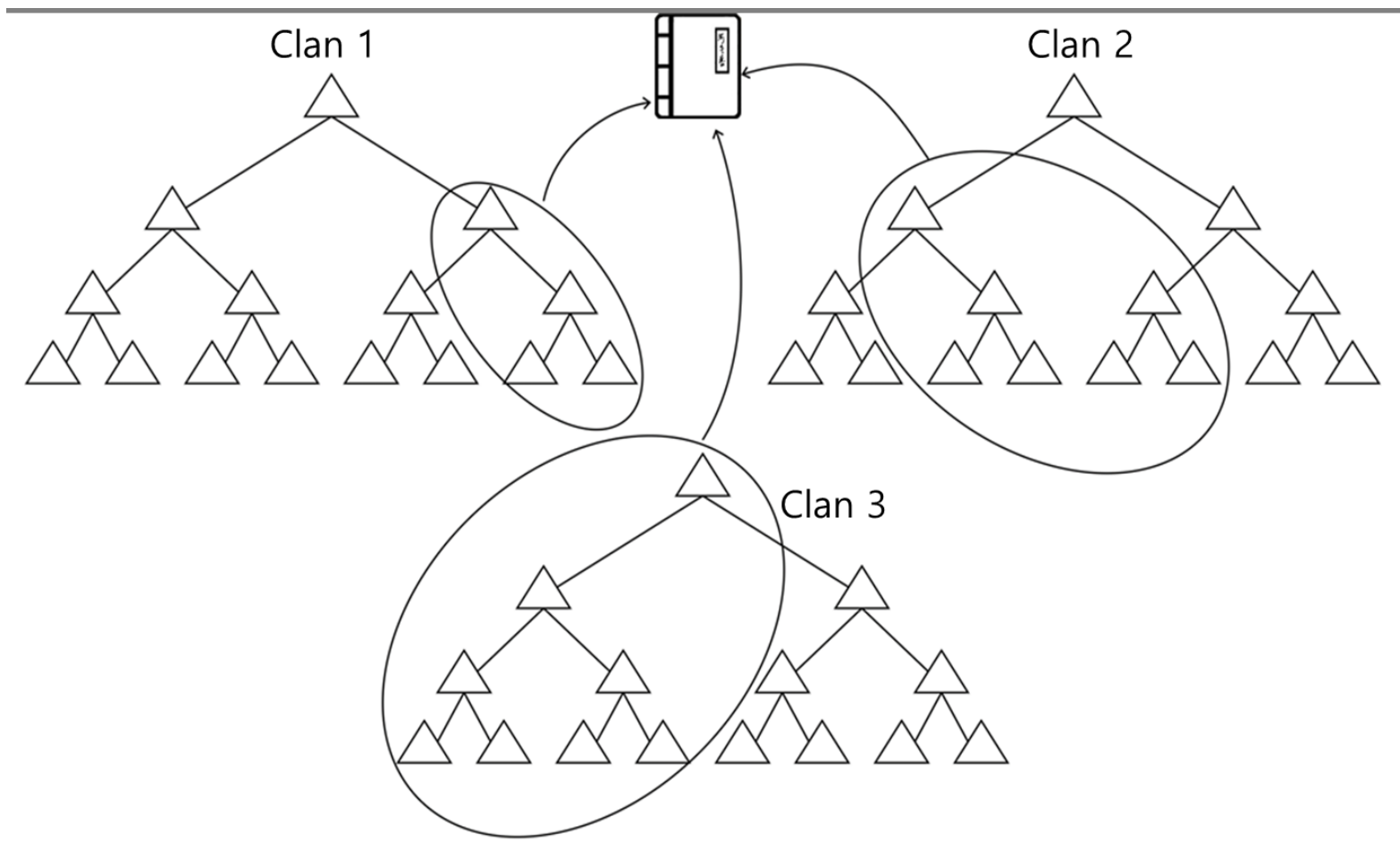

Figure 3 Chonghappo

\footnotetext{
* Korean words in this paper are romanized according to the McCune-Reischauer system.

${ }^{1}$ Hankuk sahoe ŭi pulp'yŏngtŭng munhwa: nama sŏnho kyŏnghyang kwa ttaltŭl ŭi hangpyŏn / wiki ŭi kapuchangche wa pulp'yŏngtŭng kucho. Yŏsŏng kachok saenghwal yŏnku pokosŏ 2 - Hankuk kachok ŭi pulp'yŏngtŭng munhwa wa kaltŭng kucho. Myŏngchi taehakkyo yŏsŏng kachok saenghwal yŏnkuso (Institute of Woman and Family Life Myong - Ji University) (2002): 11-56.

${ }^{2}$ Ch'oe, Chaesŏk (Choi, Jai Seuk). Han'guk kajokchedosa yŏn'gu. Seoul: Ilchisa (1983); Deuchler, Martina. The Confucian Transformation of Korea: A Study of Society and Ideology. Harvard University Asia Center (1992); Peterson, Mark A. Korean Adoption and Inheritance: Case Studies in the Creation of a Classic Confucian Society. Cornell East Asia Series 80 (1996).

${ }^{3}$ Kwŏn, Kisŏk (Kwon, Kiseok). Chokpo wa Chosŏn sahoe: 15 17segi kyebo ŭishik ŭi pyŏnhwa wa sahoegwan'gyemang (Genealogy and Chosŏn Society: The Transformation of Genealogical Consciousness and Social Networks from the 15th to the 17th Century). Seoul: Taehaksa (2010). For an overview of the issue and current debates in Korean language scholarship, see Kwŏn, Naehyeon (Kwon, Nae-Hyun). "Chosŏn huki pukye kachok ch'inchok ŭi hwaksan kwa myŏch' kachi munche." Hankuksa hakpo no.62 (2016); 248-251.

${ }^{4}$ Son, Pyŏnggyu (Son, Byung Giu). "20seki ch'o Hankuk ŭi chokpo p'yŏnch'an kwa tongchok chiptan kusang Kyŏngsangto Tansŏng chiyŏk Antong Kwŏnssi myŏch' kakye ŭi salye (The Compilation of Genealogy and the Embodiment of Lineage Group in Early $20^{\text {th }}$-Century Korea)." Taedong munhwa yŏn'gu (Journal of Eastern Studies) no.91 (2015); 65-92; Chin, Sangwŏn (Jin, Sang-Won). "Chosŏn huki Tonglae Sasang myŏn Haman Chossi kamun ŭi kakye punhwa wa sahoe chiwi ŭi ch'ai mich' chongchok hwaŭi tu panghyang (Lineage Differentiation of Haman Cho's Family, Lived in Sasangmyeon Dongnae in the Late Joseon Dynasty, and Their Social Status Difference and Two Directions of Making Lineage)." Hankuk minchok munhwa 55 (2015); 3-46.

${ }^{5}$ Yi, Chongsŏ (Lee, Jongseo). "Koryŏhugi ihu tonggi iron ŭi chŏn'gae wa hyŏryŏn ŭishik ŭi pyŏndong (Emergence
} 
of the 'Shared Spirit' Theory and Changes in Consciousness of Blood Lineage Consciousness from the Latter Half of the Koryŏ Period)." Tongbang hakchi (The Dongbanghakchi) 120 (2003); 1-35; Han, Sangu (Han, Sangwoo). Chosŏn huki yangpanch'üng ŭi ch'inchok net'üwŏk'ü (The Kin Network of the Yangban Elite of the Late Joseon Dynasty). Ph.D. diss. Sungkyunkwan Universtiy (2015); Paek, Kwangryŏl (Baek, Kwang Ryeol). Chosŏnhuki

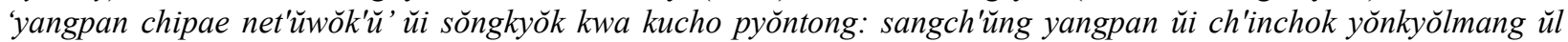
chungsim ŭlo (The Character and Structure of the 'Yangban Domination Network' in the Late Joseon Period: Focused on the Kinship Network of Upper Man). Ph.D. diss. Seoul National University (2017).

${ }^{6}$ Kishimoto, Mio et al. Chosŏn kwa Chungkuk kŭnse obaengnyŏn ŭl kada: ilguksa rŭl nŏmŏsŏn Tongasia ilkki. Seoul: Yeoksa bipyeongsa (2003)

${ }^{7}$ The Richard Wilhelm translation rendered into English by Cary F. Baynes; foreword by C.G. Jung. preface to the third edition by Hellmut Wilhelm. The I Ching or Book of Changes. Routledge and Kegan Paul (1973); 382. Ch'ien, on nine in the fifth place: “同聲相應 同氣相求.”

${ }^{8}$ Ch'oe, Chaesŏk (Choi, Jai Seuk). Han'guk kajokchedosa yŏn'gu; Deuchler, Martina. The Confucian Transformation of Korea: A Study of Society and Ideology.

${ }^{9}$ Park, Insook Han, and Lee-Jay Cho. "Confucianism and the Korean Family." Journal of Comparative Family Studies (1995): 117-134.

${ }^{10}$ Inoue, Tōru. Chūgoku no sōzoku to kokka no reisai; shūhōshugi no shiten kara no bunseki (The Clan and the State in China). Tokyo: Kenbunshuppan (2000); Miyajima, Hiroshi. "Tongashia segye sok ŭi Han'guk chokpo (Korean Genealogy in the World of East Asia)." Taedong munhwa yŏn'gu (Journal of Eastern Studies) no.77 (2012): 7-28.

${ }^{11}$ Chang, Jian Hua. "Myŏngmal hwabuk chongjok kwa chongjogk ŭi chaeguch'uk (Reconstruction of the Clan and Genealogy in North China in the Late Ming Dynasty - Taking the Revised Xing Genealogy of Qingzhou as an Example)." Taedong munhwa yŏn'gu (Journal of Eastern studies) no.77 (2012): 67-107.

${ }^{12}$ Yuk, Chŏngim (Yuk, Jung im). "Songwŏndae chokpo such'an kwa kŭ sahoesajŏk ŭiŭi (Compilation of Genealogy in the Song-Yuan Period and its Socio-Historical Significance)." Han'guksa hakpo (The Journal for the Studies of Korean History) no.22 (2006): 233-270.

${ }^{13}$ Miyajima, Hiroshi. “Tongashia segye sok ŭi Han'guk chokpo,” 12.

${ }^{14}$ Ueda, Makoto. Dentoū Chūgoku; Bonchi, sōzoku ni miru Min-Shin jidai. Kodansha (1995): 111; Inoue, Tōru. Chügoku no sōzoku to kokka no reisai: shuhoshūgi no shiten kara no bunseki, 135.

${ }^{15}$ Ebrey, Patricia Buckley. Family and Property in Sung China: Yuan Ts' ai's Precepts for Social Life. Princeton: Princeton University Press (1984).

${ }^{16}$ Elman, Benjamin A. Civil Examinations and Meritocracy in Late Imperial China. Cambridge: Harvard University Press (2013).

${ }^{17}$ Pak, Wŏnho (Park, Wonho). Myŏngch'ŏng Hwiju chongjoksa yŏn'gu (Lineage in Huizhou During the Ming and Qing Periods). Seoul: Chishik sanŏpsa (2002).

${ }_{18}^{18}$ Wŏn, Chŏngsik (Won, Jeong Sik). "Myŏng chunggi Pokkŏn ŭi shinhyŏn sŏlch'itwi unyŏng kwa chongjoksahoe (The Construction and Management of New District and the Lineage Society in Mid-Ming Fujian)." Myŏngch'ŏngsa yŏn'gu (Journal of Ming-Qing Historical Studies) 27 (2007): 101-152.

${ }^{19}$ Miyajima, Hiroshi. "Tongashia segye sok ŭi Han'guk chokpo," 11-13.

${ }^{20}$ Tsubouchi, Reiko. Keishō no jinkō shakaigaku (Social Demography of Family Succession). Tokyo: MINERVA shobō (2001).

${ }^{21}$ Son, Pyŏngkyu (Son, Byung Giu). "Ryugu wangguk kwa Chosŏn wangjo chokpo ŭi pigyo yŏn'gu (Comparative Study of Ryukyu and Chosŏn Genealogy).” Taedong munhwa yŏn'gu (Journal of Eastern Studies) 94 (2016): 41-70.

${ }^{22}$ Suenari, Michio. "Betonamu no 'kafu' (Genealogy of Vietnam)." Tōyōbunka kenkyusho kiyō 127 (1995); Miyajima, Hiroshi. "Tongashia segye sok ŭi Han'guk chokpo," 15.

${ }^{23}$ Van Luong, Hy. "Vietnamese Kinship: Structural Principles and the Socialist Transformation in Northern Vietnam." The Journal of Asian Studies 48, no. 4 (1989): 741-756; Nguyen, Tuan Anh. Kinship as Social Capital: Economic, Social and Cultural Dimensions of Changing Kinship Relations in a Northern Vietnamese Village. Ph.D. diss. Vrije Universiteit Amsterdam (2010).

${ }^{24}$ For more information see, Yu, In-sŏn. Law and Society in Seventeenth and Eighteenth Century Vietnam. Seoul: Asiatic Research Center, Korea University (1990): p.4.

${ }^{25}$ Nguyen, Thi Mai Hoa. Viet Nam's Genealogy and its Value. M.A. diss. Sungkyunkwan Univ. (2011): 31, 38.

${ }^{26}$ Ibid. 5 .

${ }^{27}$ Yu, In-sŏn. Law and Society in Seventeenth and Eighteenth Century Vietnam. 67; Han, Tohyŏn (Han, Do Hyun). 
"Han'guk kwa Pet'ǔnam ŭi tu chongjongmaŭl (tongsŏngmaŭl) ŭi chongjok ŭishik pigyo yŏn'gu (Comparative Study of the Lineage Consciousness of Two Lineage Villages in Vietnam and Korea)." Nongch'on sahoe 17 No.2 (2007): 129.

${ }^{28}$ Yu, In-sŏn. Law and Society in Seventeenth and Eighteenth Century Vietnam. 66.

${ }^{29}$ Keyes, Charles F. The Golden Peninsula: Culture and Adaptation in Mainland Southeast Asia. Honolulu: University of Hawaii Press (1995).

${ }^{30}$ Collection of the National Library of Korea (Call number: 한ㅁㅁ 朝58-가50-304).

${ }^{31}$ Collection of the Kyujanggak Institute for Korean Studies (Call number: 古貴 929.1-Se61a-v.1-3)

${ }^{32}$ Miyajima, Hiroshi. "Andong Kwŏnssi sŏnghwabo rŭl t'onghaesŏ pon Han'guk chokpo ŭi kujojŏk t'ŭksŏng (The Structural Characteristics of Korean Genealogy: A Case Study on Andong Kwŏn-ssi Sŏnghwabo).” Taedong munhwa yŏn'gu (Journal of Eastern Studies) 62 (2008): 201-241; Park, Hyunjoon, and Sangkuk Lee. "A Survey of Data Sources for Studies of Family and Population in Korean History." The History of the Family 13, no. 3 (2008): 258267.

${ }^{33}$ In the possession of the Munhwa Ryu Clan association.

${ }^{34}$ In the possession of the head house of the descendants of the compiler, Hon Ha.

${ }^{35}$ Son, Pyŏnggyu (Son, Byung Giu). "Chosŏn wangjo 1600nyŏn'gyŏng p'yŏnch'an chokpo ŭi kyebo hyŏngt'ae wa t'ǔksŏng -1606nyŏn p'yŏnch'an ${ }^{『}$ Chinyang Hassi sebo (mallyŏkpon)』 ŭi punsŏk ŭl chungshim urro (The Form and Characteristics of Pedigree in the 1600's Genealogy of the Joseon Dynasty - Focusing on the ${ }^{『}$ Chinyang Hassi Genealogy (Mallyo edition)』 Made in 1606).” Taedong munhwa yŏn'gu (Journal of Eastern Studies) no. 77 (2012): 109-140.

${ }^{36}$ Son, Pyŏnggyu (Son, Byung Giu). "Chokpo esŏ ponŭn wangshil kwaŭi honin kirok kwa kyebo hyŏngt'ae (The Form of Lineage Records and Recordings of Marriage with the Royal Family as Seen Through Genealogies)." Changsŏgak 27 (2012): 65-92; Kim, Sŏngo (Kim, Sungoh). 17segi Hapch'ŏn chiyŏk yangban ŭi honin net'ŭwŏk'ŭ (Marriage Network of Yangban Families of Hapch'ón in the 17th Century). M.A. diss. Sungkyunkwan University (2017).

${ }^{37}$ Yi, Sugŏn (Lee, Soogeon). "Chokpo wa yangban ŭishik." Han'guksa shimin kangjwa (The Citizens' Forum on Korean History) 24 (1999): 20-49.

${ }^{38}$ Ch'oe, Chaesŏk (Choi, Jai Seuk). Han'guk kajokchedosa yŏn'gu, 706-710.

${ }^{39}$ Kwŏn, Kisŏk (Kwon, Kiseok). Chokpo wa Chosŏn sahoe: 15 17segi kyebo ŭishik ŭi pyŏnhwa wa sahoe gwan'gyemang (Genealogy and Chosŏn Society: The Transformation of Genealogical Consciousness and Social Networks from the 15th to the 17th Century). Seoul: Taehaksa (2010).

${ }^{40}$ Andong Kim ssi sebo (1878) is a collection of the Jon'gyeong'gak Library of Sungkyunkwan University (B10B0289); Pŏmnye (Introductory notes), "In the latest genealogy, only the surviving wife wrote down the name of her father and maternal grandfather. But from now on everyone writes the names of four forefathers of the wife's side." Collection of Chon'gyŏnggak, Sungkyunkwan University.

${ }^{41}$ Son, Pyŏnggyu (Son, Byung Giu). Hojŏk (The Household Register), Seoul: Humanist (2007).

${ }^{42}$ Ch'oe, Yanggyu (Choi, Yang-Kyu). Han'guk chokpo paltalsa, Seoul: Hyean (2011).

${ }^{43}$ Song, Chunho (Song, Jun Ho). Han'guk sahoesa yŏn'gu. Seoul: Ilchogak (1987).

${ }^{44} \mathrm{Yi}$, Chongsŏ (Lee, Jongseo). Koryŏ, Chosŏn ŭi ch'injok yongŏ wa hyŏryŏn ŭishik: ch'injokkwan'gye ŭi chŏnghyŏng kwa pyŏndong. Seoul: Sin'gu munhwasa (2009).

${ }^{45}$ Pak, Pyŏngnyŏn (Park, Byungryun). "Han'guk ŭi chŏnt'ongsahoe wa chokpo ilkki." Changsŏgak no.1 (1999): 119135 .

${ }^{46}$ Eugene Park translated taedongbo as "comprehensive genealogy" in his book. Park, Eugene Y. A Genealogy of Dissent: The Progeny of Fallen Royals in Chosŏn Korea. Stanford University Press (2018): 7.

${ }^{47}$ Especially see Deuchler's work. Deuchler, Martina. Under the Ancestors' Eyes: Kinship, Status, and Locality in Premodern Korea. Cambridge: Harvard University Asia Center (2015); 288.

${ }^{48}$ Collection of the central library of Kyunpook National University (Call number: 929.2 안225김人(3)).

${ }^{49}$ Collection of the National Library of Korea (Call number: 古2518-10-1020).

${ }^{50}$ Collection of the National Library of Korea (Call number: 한무웅 58 -가5-486), 
${ }^{51}$ Collection of the Jon'gyeong'gak Library of Sunkyunkwan University (Call number: B10B-0289).

${ }^{52}$ There is a copied version in the Bucheon Jokbo Library (Call number: 021-1926-022).

${ }^{53}$ Andong Kim ssi sebo (1926); Pŏmnye (Introductory notes) "14. We have not recorded the segment that appears in the extra volume of the last edition because they do not wish to be recorded in the new edition." The descendants of Sansu Kim do not appear from the fifth edition in 1926, but the fourth edition in 1878 recorded this segment until the 14th generation from Sansu.

${ }^{54}$ Han, Sangu (Han, Sangwoo). "Hojŏk ŭro pon Tansŏng Hapch'ŏn Yissidŭl ŭi kongjon kwa paeje yangsang (Coexistence and Disputes between the Danseong Region's Hapcheon Yi Kinship Members, Based on an Examination of the Household Registers)." Yŏksa wa hyŏnshil (Quarterly Review of Korean History) no.65 (2017): 283-314.

${ }^{55}$ Han, Sangu (Han, Sangwoo). "Chokpo ŭi kyebo rŭl t'onghae pon ch'injok kyŏlchip ŭi isang kwa hyŏnshil (The Ideal and Reality of the Solidarity of Patrilineal Kin in Genealogies of the Hapch'ŏn Yi Clan)." Sarim 65 (2018): 2956.

${ }^{56}$ Son, Pyŏnggyu (Son, Byung Giu). “Chokpo ŭi in'gu kijae pŏmwi - 1926nyŏn'gyŏng e chaksŏngdoen Hapch'ŏn Yissi ŭi se p'abo rŭl chungshim urro (The Extent of a Genealogical Record - Focused on Three Branch Records of the Yi of Hapch'ŏn Written Around 1926)." Komunsŏ yŏn'gu (The Journal of Korean Historical Manuscripts) 28 (2006): 265-298.

${ }^{57}$ Waltner, Ann. "Widows and Remarriage in Ming and early Qing China." Historical Reflections (1981): 129-146. Especially see note 20 .

58 “以別尊卑.” Yŏnan Yi ssi chokpo (1729), Pŏmnye (Introductory notes); a collection of the National Library of

Korea (Call number: 한古朝58-가33-228); Sunch'ŏn Pak ssi chokpo (1858), Pŏmnye; a collection of the Jon'gyeong'gak Library of Sunkyunkwan University (Call number: B10B-0544)

${ }^{59}$ Song describes ch'onghappo as one of the unique patterns of Korean genealogies, unlike Chinese and Japanese genealogies. See Song, Chunho (Song, Jun Ho). Han'guk sahoesa yŏn'gu. 63-65.

${ }^{60}$ Ch'a, Changsŏp (Cha, Jang Sup). "Chosŏnshidae chokpo ŭi yuhyŏng kwa t'ŭkching (The Types and Unique Features of Korean Genealogies).” Yǒksa kyoyuk nonjip (History Education Review) no.44 (2010): 239-278.

${ }^{61}$ Collection of the library of Korean Studies of the Academy of Korean Studies (Call number: B10B-46).

${ }^{62}$ Collection of Korea University Library (Call number: 대학원 B13 A42 1-10).

${ }^{63}$ A facsimile edition can be found in the National Library of Korea (Call number: 999.11 만 12).

${ }^{64}$ Collection of the library of Korean Studies of the Academy of Korean Studies (Call number: K2-1751).

${ }^{65}$ Collection of the Jon'gyeong'gak Library of Sunkyunkwan University (Call number: B10B-0117).

${ }^{66}$ Collection of the Jon'gyeong'gak Library of Sunkyunkwan University (Call number: B10B-0021).

${ }^{67}$ Collection of the National Library of Korea (Call number: 999.81-보423ㅎ-1).

${ }^{68}$ There are many versions of Chamyongbo. Two of them are in the possession of the Jon'gyeong'gak Library of Sunkyunkwan University (Call number: B10B-0235, B09C-0176).

${ }^{69}$ One of the many versions of Chinshinbo can be found in the Jon'gyeong'gak Library of Sunkyunkwan University (Call number: 성헌 B09D-0004).

${ }^{70}$ The Jon'gyeong'gak Library of Sunkyunkwan University houses some of Munbo versions (Call number: B10B0022, B10B-0264, B10B-0324).

${ }^{71}$ One of the many versions is in the possession of the National Library of Korea (Call number: 한 古朝58-나7).

${ }^{72}$ Some versions are held by the Jon'gyeong'gak Library of Sunkyunkwan University (Call number: B10B-0048, B10B-0048a, B10B-0271).

${ }^{73}$ Two versions are available at the Jon'gyeong'gak Library of Sunkyunkwan University (Call number: 손영준 B10B-0291, B10B-0016).

${ }^{74}$ One of the copies of Pukpo is available at the Jon'gyeong'gak Library of Sunkyunkwan University (Call number: B10B-0035).

${ }^{75}$ For overviews of various kinds of ch'onghappo, see Ch'a, Changsŏp (Cha, Jang Sup). "Chosŏnshidae chokpo ŭi yuhyŏng kwa t'ǔkching."; Kim yŏngin (Kim, Young Jin), "Chosŏnhuki tangp'apo yŏnku: pukpo lŭl chungsim ŭlo."Hankukhak nonchip no. 44 (2011): 299-348; “Chosŏnhuki tangp'apo yŏnku (2): Nambo (Research on the Party 
Genealogy of the Latter Period of the Choson Dynasty (2) - Focusing on the Genealogy of the South Party Choson)." Taedong munhwa yŏn'gu (Journal of Eastern Studies) no. 94 (2016): 71-94; Pak, Hongkap (Park, Hong-Gab). Uli sŏngssi wa chokpo iyaki: chokpo lŭl t'onghae pon hankukin ŭi chŏngch'esŏng. Sanch'ŏlŏm (2014).

${ }^{76}$ For more information about the characteristics, structure, and limitation of Mansong taedongbo see Paek, Kwangryŏl (Baek, Kwang Ryeol). Chosŏnhuki 'yangpan chipae net'ǔwŏk'ü' ŭi sŏngkyŏk kwa kucho pyŏntong: sangch'üng yangpan ŭi ch'inchok yŏnkyŏlmang ŭl chungsim ŭlo; 53-69.

${ }^{77}$ Sometimes male members of a lineage would blame women for disorder and divergence among family members. Watson, Rubie S. Inequality Among Brothers: Class and Kinship in South China. Cambridge: Cambridge University Press (2007); See also examples contained in Mann, Susan. "Grooming a Daughter for Marriage: Brides and Wives in the Mid-Ch'ing Period." Marriage and Inequality in Chinese Society. University of California Press (1991) n.22, p.226.

${ }_{78}^{78}$ Son, Pyŏnggyu (Son, Byung Giu). Hojŏk, 41.

${ }^{79}$ Available at the Jon'gyeong'gak Library of Sunkyunkwan University (Call number: B09C-0379).

${ }^{80}$ Miyajima, Hiroshi. "Tongashia segye sok ŭi Han'guk chokpo (Korean Genealogy in the World of East Asia)," 2122.

${ }^{81}$ Lee, Sangkuk, and Wonjae Lee. "Strategizing Marriage: A Genealogical Analysis of Korean Marriage Networks." Journal of Interdisciplinary History 48, no.1 (2017): 1-19.

${ }^{82}$ Sunch'ŏn Pak ssi sebo (1899) is a collection of the National Library of Korea (Call number: 古2518-25-366).

${ }^{83}$ Andong Kim ssi sebo (1878); Pŏmnye (Introductory notes).

${ }^{84}$ Miyajima, Hiroshi. "Chosŏnshidae ŭi shinbun, shinbunje kaenyŏm e taehayŏ (A Study on the Concepts of a Person's Status and the Status System in the Joseon Period)." Taedong munhwa yŏn'gu (Journal of Eastern studies) no. 42 (2003): 289-308. 